\title{
Endoscopy in achalasia
}

\author{
W. ROESCH \\ M.D. \\ Department of Medicine, University of Erlangen-Nüremberg, West Germany
}

\section{Summary}

In achalasia oesophagoscopy should be used to rule out definitely carcinoma of the cardia involving the myenteric plexus of the lower oesophageal sphincter. An easy passage of the instrument through the narrow terminal segment is characteristic but not always possible due to extreme distortion. Syncopal attacks are rarely encountered.

ENDOSCOPY has a very limited role in the diagnosis of achalasia but should always be undertaken when the radiologist suggests this diagnosis. The inspection of the oesophagus may be impaired by marked retention of food particles; we therefore lavage the organ routinely before starting endoscopy. Oesophagoscopy is principally used to rule out a stenosing process at the oesophago-cardiac junction simulating achalasia, but may also reveal some features which are thought to be pathognomonic. A marked dilation of the oesophagus, segmental contractions and lack of peristalsis may point to the correct diagnosis as do radiating folds towards a permanently closed cardia, but these criteria can be much better diagnosed in radiological studies. The only criterion which might be of some importance is the easy passage of the instrument through the narrow segment which apparently opens just by touching it with the tip of the oesophagoscope. Whenever this passage is impossible a peptic stricture, an undermining carcinoma of the cardia or an intramural process are to be suspected.

The endoscopic examination of the patient with suspected achalasia is incomplete unless a thorough inspection of the cardia from the stomach is performed. The U-turn manoeuvre with guided biopsies from abnormal looking lesions is probably the most important contribution of endoscopy in the diagnosis of achalasia. There are several reports in the literature that the typical radiological (Kolodny et al., 1968) and manometric (Herrara et al., 1970) pattern, even with positive mecholyl test was caused by an infiltrating carcinoma destroying the intramural plexus.

Endoscopic short-term follow-up studies after mechanical or pneumatic dilatation to recognize reflux-oesophagitis in its early stages are rarely performed. Since carcinoma of the proximal oesophagus may be a complication of long-standing achalasia with a reported incidence of $1 \cdot 7-8 \cdot 2 \%$ (Seliger, Lee and Schwartz, 1972) periodic oesophagoscopy with active search for neoplasm is advisable.

It has been postulated that diffuse oesophageal spasm may represent an early phase of achalasia in view of the inco-ordinated peristaltic contractions and the positive response to mecholyl (Kramer, Harris and Donaldson, 1967). Oesophagoscopy does not contribute to the differential diagnosis of these disorders, but may be very useful in removing an impacted meat bolus in oesophageal spasm.

Finally I would like to mention the rare occurrence of syncopal attacks in achalasia in relation to the intake of food. We had the opportunity to observe a 38-year-old man who developed total atrio-ventricular block with Stokes-Adams attacks which were reproducible by distention of the terminal oesophagus. The patient had to be treated with a QRSregulated pacemaker before mechanical dilatation of the oesophago-gastric junction could be performed without complications (Roesch, Bachmann and Ottenjann, 1970). Cardiac syncope however, has also been reported in association with oesophageal tumour, oesophageal diverticulum, oesophageal spasm and oesophageal stricture and seems therefore of minor importance in the diagnosis and management of achalasia (Tolman and Ashworth, 1971).

\section{References}

Herrara, A.F., Colon, J., Valdes-Dapena, A. \& Roth, J.L.A. (1970) Achalasia or carcinoma? The significance of mecholyl test. American Journal of Digestive Diseases, 15, 1073.

Kolodny, M., Schrader, Z.R., Rubin, W., Hockman, R. \& Sleisenger, M.H. (1968) Esophageal achalasia probably due to gastric carcinoma. Annals of Internal Medicine, 69, 569.

Kramer, P., Harris, L.D. \& Donaldson, R.M. (1967) Transition from symptomatic diffuse spasm to cardiospasm. Gut, 8, 115 .

Roesch, W., Bachmann, K. \& Ottenjann, R. (1970) Achalasia with asystolic cardiac arrest. German Medical Monthly, 15, 386.

Seliger, G., Lee, T. \& Schwartz, S. (1972) Carcinoma of the proximal esophagus a complication of long-standing achalasia. American Journal of Gastroenterology, 57, 20.

Tolman, K.G. \& AshworTh, W.D. (1971) Syncope induced by dysphagia. American Journal of Digestive Diseases, 16, 1026. 